\title{
The variability in the carbon sinks as reconstructed for the last 1000 years
}

\author{
Fortunat Joos, Robert Meyer, Michele Bruno, Markus Leuenberger \\ Climate and Environmental Physics, Physics Institute, University of Bern, Bern, Switzerland
}

\begin{abstract}
The atmospheric $\mathrm{CO}_{2}$ and $\delta^{13} \mathrm{C}$ records for the last millennium have been analyzed to reconstruct the evolution and the temporal variability in the terrestrial and oceanic carbon sinks and to identify natural variations in the marine carbon cycle. Reconstructed natural variations in sinks are usually less than $\pm 0.2 \mathrm{Gt} \mathrm{C} \mathrm{yr}^{-1}$ on time scales of decades to centuries and thus one order of magnitude smaller than the sink fluxes driven by the anthropogenic perturbation. The natural oceanic carbon cycle was generally close to steady state on a multi-decadal time scale. A large anomalous oceanic carbon sink is found around 1940 that is attributed to a higher than usual El Niño activity. Interannual variations in the oceanic sink as reconstructed for the 1980-1996 period are around $\pm 1 \mathrm{Gt} \mathrm{C} \mathrm{yr}^{-1}$ and are significantly correlated with the Southern Oscillation. The relatively low atmospheric $\mathrm{CO}_{2}$ concentrations between 1600 and 1750 were caused by an additional terrestrial storage of $40 \mathrm{Gt} \mathrm{C}$. The land biota acted as a carbon source between 1750 and 1950 and as a sink afterwards. Terrestrial changes can be explained by land use emission up to 1920. Then, additional mechanisms such as $\mathrm{CO}_{2}$ fertilization are responsible for an estimated terrestrial sequestration of 100 Gt $C$ between 1920 and 1996 .
\end{abstract}

\section{Introduction and Methods}

Much of the recent debate over the global carbon cycle has been related to the interannual and regional variability of carbon sinks during the last few years while much less attention has been given to reconstruct the long-term variability in sinks. Here, we provide a synthesis view of the evolution of the carbon sinks during the last millennium and their variabilities on centennial to interannual time scales.

Recently, high-precision and high-resolution measurements of $\mathrm{CO}_{2}$ and $\delta^{13} \mathrm{C}$ have been obtained from firn (1976-1993) and ice (1005-1975) at a high-accumulation site at Law Dome Antarctica [Etheridge et al., 1996; Francey et al., 1999]. These data cover the last millennium including the industrial period and overlap with measurements obtained on atmospheric samples [Kecling et al., 1995; Francey et al., 1995; Francey et al., 1999] (Fig. 1). The precision of the new $\delta^{13} \mathrm{C}$ data is increased by a factor of 4-8 as compared to previous ice core records. The Law Dome $\delta^{13} \mathrm{C}$ record is also the first record that covers the period from 1950 to 1980. This allows us for the first time to deconvolve the terrestrial and oceanic sink fluxes from $\delta^{13} \mathrm{C}$ data over the entire millennium and to update an earlier reconstruction for the industrial period that suffered from the lack of $\delta^{13} \mathrm{C}$ data between 1950 and 1980 [Joos and Bruno, 1998]. Our results complement those of Indermühle et al. [1999] who have reconstructed millennial scale variations in the global carbon cycle for the last 11'000 years using the same method and model as in this study.

We have analyzed the new data using an inverse method referred to as 'double deconvolution' [Joos and Bruno,

\section{Copyright 1999 by the American Geophysical Union.}

Paper number 1999GL900250 0094-8276/99/1999GL900250\$05.00
1998; Keeling et al., 1995; Francey et al., 1995]. The two atmospheric budget equations for $\mathrm{CO}_{2}$ and ${ }^{13} \mathrm{C}$ are solved for the two unknown global sink (source) fluxes into the ocean and the terrestrial biosphere. The $\mathrm{CO}_{2}$ budget yields the total sink flux into ocean plus biosphere to equal the change in atmospheric inventory minus fossil emissions. The ${ }^{13} \mathrm{C}$ budget is used to partition between the oceanic and terrestrial sink fluxes that carry different isotopic signatures. Isotopic disequilibrium fluxes are estimated with the Bern model [Siegenthaler and Joos, 1992]. Model parameters are as in Joos and Bruno [1998] except that global net primary productivity has been increased from 60 to $70 \mathrm{Gt} \mathrm{C} \mathrm{yr}^{-1}$. Variations in sea surface temperature (SST) were prescribed according to observations [Parker et al., 1995; Mann et al., 1998] to calculate the temperature dependency of air-sea fractionation factors [Mook, 1986], of surface water $\mathrm{pCO}_{2}$ [Takahashi et al., 1993], and related changes in isotopic disequilibria. The atmospheric concentrations (Fig. 1), their derivatives and fossil emissions [Marland et al., 1995; Andres et al., 1996] are prescribed from observations. The input data have been splined [Enting, 1987] using approximate cut-off periods of 300 years prior 1850 and of 40 years afterwards as motivated by the $\delta^{13} \mathrm{C}$ data frequency and the age distribution of air enclosed in ice. The cut-off period depends only weakly on the data spacing. The more frequent atmospheric observations (1980-1996) have also been splined by a cut-off period of 4 years instead of 40 years to reconstruct interannual variability in sinks. Results are similar for ice core and atmospheric data if input data are linearly interpolated and model output is smoothed instead of input. We emphasize that the variabilities in sinks are not directly comparable for periods of different smoothing.

The 1- $\sigma$ uncertainties in the decadal average sinks associated with uncertainties in disequilibrium fluxes $( \pm 0.6 \mathrm{Gt}$ $\left.\mathrm{C} \mathrm{yr}^{-1}\right)$, fractionation factors $\left( \pm 0.5 \mathrm{Gt} \mathrm{C} \mathrm{yr}^{-1}\right)$, fossil emissions $\left( \pm 0.3 \mathrm{Gt} \mathrm{C} \mathrm{yr}^{-1}\right)$, and atmospheric $\mathrm{CO}_{2}$ and $\delta^{13} \mathrm{C}( \pm 0.1$ Gt C yr ${ }^{-1}$; Fig. 2) are estimated to be $\pm 0.8 \mathrm{Gt} \mathrm{C} \mathrm{yr}^{-1}$ for the most recent decades; they are less than $\pm 0.3 \mathrm{Gt} \mathrm{C}$ $\mathrm{yr}^{-1}$ prior to 1950 (see Joos and Bruno [1998]). Results may be affected by climatically induced changes in the airbiota isotopic discrimination. The sensitivity of our results to changes in the marine biological cycle that modify air-sea disequilibria is investigated below.

The classical method to establish the historical balance of carbon sources and sinks is to use an ocean transport model to calculate the oceanic uptake of carbon and to solve the atmospheric carbon budget equation for the unknown terrestrial sink or source [Siegenthaler and Oeschger, 1987; Bruno and Joos, 1997; Trudinger et al., 1999]. We have also applied this method referred to as 'single deconvolution'. 1- $\sigma$ uncertainties in sinks associated with uncertainties in atmospheric $\mathrm{CO}_{2}$, ocean transport, and fossil emissions are estimated to be less than $\pm 0.2 \mathrm{Gt} \mathrm{C} \mathrm{yr}^{-1}$ prior to 1950 and $\pm 0.5 \mathrm{Gt}$ $\mathrm{C} \mathrm{yr}^{-1}$ for the 1980 decade [Bruno and Joos, 1997]. The oceanic sink fluxes are forced by atmospheric $\mathrm{CO}_{2}$ (Fig. 1, solid) and sea surface temperature (SST) variations only. Thus, potential differences in ocean uptake variability for single and double deconvolution will be attributed to variations in the natural marine carbon cycle, thereby estimating its natural variability. 


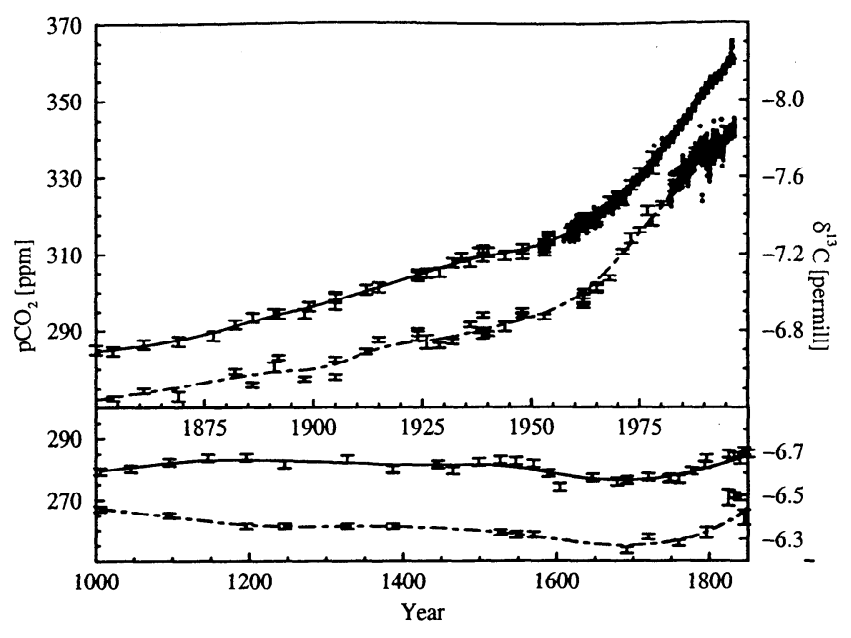

Figure 1. Atmospheric $\mathrm{CO}_{2}$ and $\delta^{13} \mathrm{C}$ histories. Data points and 1- $\sigma$ measurement errors are indicated by error bars. $\mathrm{CO}_{2}$ data are from the Law Dome ice (1005-1975 A.D.; typical 1- $\sigma$ error: $1.2 \mathrm{ppm}$ ) and firn (1976-1993, 1.2 ppm) records [Etheridge et al., 1996] and monthly averaged $\mathrm{CO}_{2}$ values from Mauna Loa and south pole (1958$1996 ; 0.1 \mathrm{ppm})$ (http://cdiac.esd.ornl.gov/trends/co2/siokeel.htm). $\delta^{13} \mathrm{C}$ data are from the Law Dome ice (0.010.025 per mill) and firn (0.01 per mill) records, from the Cape Grim air archive (1978-1996, 0.01 per mill), and insitu measurements at Cape Grim (1982-1996, 0.01 per mill). [Francey et al., 1995; Francey et al., 1999]. The $\mathrm{CO}_{2}$ (solid) and $\delta^{13} \mathrm{C}$ data (dot-dash) were spline fitted [Enting, 1987]. Note that the scale for $\delta^{13} \mathrm{C}$ has been inverted.

\section{Results}

Reconstructed centennial average sink fluxes are small prior to 1800 . The biosphere and ocean may have acted either as a small sink or source ( Fig. 2) until 1500 A.D. Then, we find for the double deconvolution a terrestrial uptake of $37 \mathrm{Gt} \mathrm{C}$ during 1500-1750 A.D. while the ocean released $29 \mathrm{Gt} \mathrm{C}$ and the atmosphere decreased by $8 \mathrm{Gt} \mathrm{C} \mathrm{(4}$ ppmv). These results support earlier suggestions [Enting, 1992; Trudinger et al., 1999] that the relatively low atmospheric $\mathrm{CO}_{2}$ level between 1600 and 1750 (Fig. 1, [Etheridge et al., 1996]) was caused by an enhanced terrestrial storage as potentially explained by a relatively stronger temperature sensitivity of heterotrophic respiration than of productivity.

After 1800, oceanic storage reflects the atmospheric $\mathrm{CO}_{2}$ rise and accumulates $131 \mathrm{Gt} C$ between 1800-1996. The land biosphere acted as a carbon source for the atmosphere between 1750 and 1950 A.D. This source can be entirely explained by carbon emissions due to land use changes [Houghton, 1993] until about 1920 (Fig. 2b). Afterwards, the biota turned from a net source into a net sink, despite continued growth of emissions from land use changes. The difference between the net sink and land use emissions amounts to $100 \mathrm{Gt} \mathrm{C}$ between 1900 and 1996. This requires a sink that has increased by $0.2 \mathrm{Gt} \mathrm{C} \mathrm{yr}^{-1}$ per decade for the Houghton [1993] land use emissions. A combination of $\mathrm{CO}_{2}$ and nitrogen fertilization and climate change provides a feasible explanation [Schimel et al., 1994].

The weakness of 'single deconvolution' reconstructions is the implicit assumption that the ocean sink is driven by atmospheric $\mathrm{CO}_{2}$ variations only and that the natural marine carbon cycle remained at steady state. The comparison between the double and single deconvolutions (Fig. 2, dashed vs. solid lines) suggests that this assumption is justified for the industrial period. Except around 1940, deviations in ocean uptake by the single and double deconvolution meth- ods (Fig. 2a) are always less than $0.2 \mathrm{Gt} \mathrm{C} \mathrm{yr}^{-1}$ when the input data are smoothed by an approximate cut-off period of 300 years (1000-1850) and 40 years (1850-1996), respectively. However, we can not exclude a natural trend in the oceanic sink for the post 1950 period because uncertainties in the reconstructions are substantial after 1950; the agreement between single and double deconvolution results is largely model dependent for the post 1950 period.

The sinks reconstructed by the double deconvolution vary between 1870 and 1960 . The growth rate in atmospheric $\delta^{13} \mathrm{C}$ as deduced from a spline with a cut-off period of 40 years varies around their long-term increase between 1870 and 1930 , thereby causing the variations in sinks before 1930. The variations in sinks are similar if a cut-off period of 20 years is applied. Unfortunately, there are only five $\delta^{13} \mathrm{C}$ data points between 1890 and 1920. A Monte Carlo analysis where the atmospheric $\mathrm{CO}_{2}$ and $\delta^{13} \mathrm{C}$ data were varied ac-
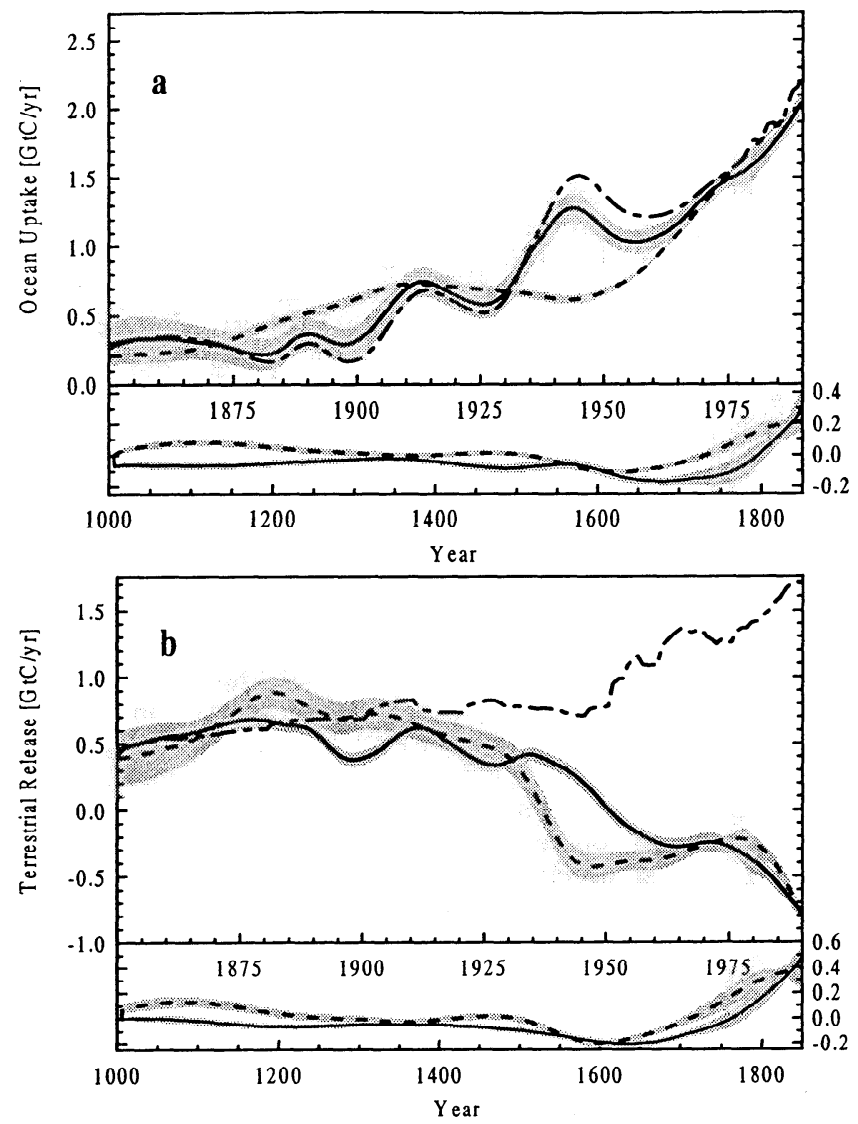

Figure 2. (a) The oceanic carbon uptake as reconstructed by inverting the atmospheric $\mathrm{CO}_{2}$ and $\delta^{13} \mathrm{C}$ history (double deconvolution; solid) and as calculated by the HILDA ocean model (single deconvolution; dash). The input data were spline fitted [Enting, 1987] using approximate cut-off periods of 300 years before 1850 and of 40 years afterwards. The dot-dashed line shows the ocean uptake for the double deconvolution when $\delta^{13} \mathrm{C}$ of sea surface DIC is varied (see text). The bands reflect 1- $\sigma$ uncertainties due to uncertainties in the atmospheric data only and as calculated by a Monte Carlo analysis [Bruno and Joos, 1997] including 2000 runs. (b) The net terrestrial carbon release obtained for the double (solid) and single deconvolution (dashed), and net emissions due to land use changes (dot-dashed) as estimated by statistical methods [Houghton, 1993] for the 1850 to 1990 period. The terrestrial release and the oceanic uptake correspond to inventory changes; actual air-sea and air-biota net fluxes are different as the weathering/sedimentation cycle is neglected in the deconvolutions [Sarmiento and Sundquist, 1992]. 
cording to their uncertainties [Bruno and Joos, 1997] reveals that the variations before 1930 may not be real but related to uncertainties in the $\delta^{13} \mathrm{C}$ record and the data treatment.

An anomalously large ocean sink is found around 1945 (Fig. 2a). This is related to a stall in the atmospheric $\mathrm{CO}_{2}$ growth rate whereas the $\delta^{13} \mathrm{C}$ trend remained roughly unchanged. The ocean sink obtained by the double deconvolution is up to $0.6 \mathrm{Gt} \mathrm{C} \mathrm{yr}^{-1}$ larger than that of the single deconvolution; cumulative uptake is $11 \mathrm{Gt} \mathrm{C}$ or $65 \%$ larger for the double than for the single deconvolution between 1930 and 1960 . Correspondingly, the observed $\delta^{13} \mathrm{C}$ decrease of 0.21 permil (1930-1960) is 0.09 permil larger than that calculated by the single deconvolution. The anomalous flux is larger than the estimated overall uncertainties for the double and single deconvolution results $\left(0.3\right.$ and $\left.0.2 \mathrm{Gt} \mathrm{C} \mathrm{yr}^{-1}\right)$. Potential uncertainties in the fossil emissions affect the calculated terrestrial source, but not the oceanic sink strength as the isotopic signature of fossil fuel is very similar to that of biospheric material and hence the $\delta^{13} \mathrm{C}$ trend constrains the sum of fossil and terrestrial fluxes.

Perhaps, unusually long and frequent El Niño/Southern Oscillation (ENSO) events lead to a decrease in equatorial $\mathrm{CO}_{2}$ outgassing and in turn to a high ocean sink and low atmospheric growth rate. Besides for the 1940 period, low $\mathrm{CO}_{2}$ growth rates are also found around 1895 [Etheridge et al., 1996]. In agreement with our hypothesis, we find that the Southern Oscillation Index (SOI, www.cru.uea.ac.uk/cru/data/soi.htm) as splined using a cutoff period of 40 years is below average between 1933-1953 and between 1885-1913.

Changes in the marine biological cycle may have changed $\delta^{13} \mathrm{C}$ of dissolved inorganic carbon (DIC). No consistency is required between deconvolved net air-to-sea flux and the air-sea partial difference of the model used to estimate disequilibrium fluxes in our standard double deconvolution. In a sensitivity analysis, surface water DIC content was changed at each time step such that the modeled air-sea partial pressure difference is consistent with the ocean uptake from the double deconvolution. The isotopic signal of the added DIC is assumed to be of marine biogenic origin. Deviations in sinks for the standard case and this test are less than $0.25 \mathrm{Gt}$ $\mathrm{C} \mathrm{yr}^{-1}$ after 1400 A.D. and always less than $0.35 \mathrm{Gt} \mathrm{C} \mathrm{yr}^{-1}$ irrespective whether reconstructed temperature changes are considered or not (Fig. 2a, dash-dot).

The interannual variability in sinks has been reconstructed for the last 15 years for which in-situ $\delta^{13} \mathrm{C}$ measurements as well as firn and air-archive data are available (Fig. 3). Interannual variations of similar magnitude occurred very likely also before 1980, but could not be reconstructed as the age distribution of air entrapped in ice is too broad.

A correlation between the Southern Oscillation Index (SOI) and the detrended terrestrial and oceanic sink is found that explains about half of the reconstructed variability $\left(\mathrm{r}^{2}=\right.$ 0.54 and 0.42 ) during the $1980-89$ period. A student t-test reveals that the slopes are different from zero on a confidence level of $95 \%$ (terrestrial sink $97.5 \%$ ). For the 198095 period, the correlation is still significant for the oceanic sink, whereas the correlation between SOI and the terrestrial sinks breaks down after 1989. The biosphere acted as a sink of the order of $1 \mathrm{Gt} \mathrm{C} \mathrm{yr}^{-1}$ during the early nineties despite the El Niño conditions.

It was suggested earlier [Francey et al., 1995; Keeling et al., 1995] that variations in the sinks during 1980-1995 were related to ENSO events, a decadal scale warming, and the Pinatubo eruption. During El Niño conditions ocean uptake is higher and the biospheric sink is reduced as explained by increased biomass burning and by a reduced upwelling in the Equatorial Pacific [Bacastow, 1976; Siegenthaler, 1990]. The Pinatubo eruption at 1991 caused northern hemisphere cooling, thereby potentially increasing terrestrial carbon sequestration by reducing heterotrophic respiration. This is consistent with the absence of a significant correlation between terrestrial sink and SOI during the early nineties.

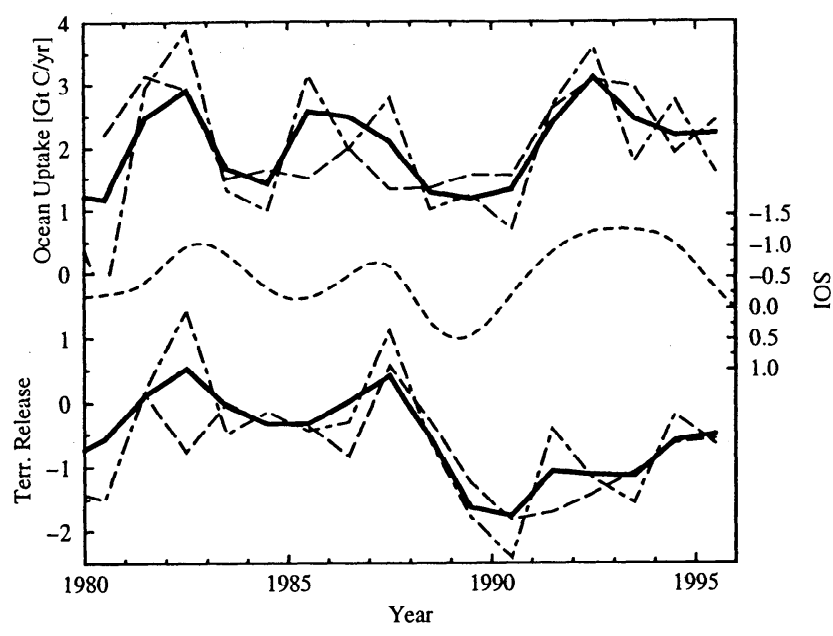

Figure 3. Annual mean oceanic carbon storage and terrestrial release as reconstructed by the double deconvolution (thick solid). The input data have been splined applying a cut-off period of 4 years, i.e. about twice the time scale of interhemispheric exchange. This cut-off period has been selected as input data from both hemispheres are used. The sinks are significantly correlated with the Southern Oscillation Index (SOI; dash) as splined with a cut-off period of 4 years. For comparison, results are shown for input data smoothed by 2 years (dot-dash) and as calculated by Rayner et al. [1999] using a Bayesian Synthesis Inversion (longdash). The standard deviation of the interannual variability in sinks is $\pm 0.6 \mathrm{Gt} \mathrm{C} \mathrm{yr}^{-1}\left(\tau_{\text {cutoff }}=4 \mathrm{yrs}\right)$ and $\pm 1 \mathrm{Gt} \mathrm{C}$ $\mathrm{yr}^{-1}\left(\tau_{\text {cutoff }}=2 \mathrm{yrs}\right)$.

The range of variability in sinks of $2 \mathrm{Gt} \mathrm{C} \mathrm{yr}^{-1}$ is smaller than that found by Francey et al. [1995] (0-4 Gt C yr $\left.{ }^{-1}\right)$ and by Keeling et al. [1995] ( $\approx 0-5 \mathrm{Gt} \mathrm{C} \mathrm{yr}^{-1}$ (period means in their Fig. $3 c$ and $d)$ ). The difference can not only be explained by different smoothing of the input data, but is also related to the use of different $\mathrm{CO}_{2}$ (Francey et al.) and different $\delta^{13} \mathrm{C}$ (Keeling et al.) data and numerical methods.

To check our numerical method, we compare our results with those of Rayner et al. [1999] who used a Bayesian Synthesis approach and an atmospheric transport model to invert atmospheric $\mathrm{CO}_{2}$ data from 12 stations, the same $\delta^{13} \mathrm{C}$ data as in this study, and $\mathrm{O}_{2} / \mathrm{N}_{2}$ data for the 1980 to 1995 period. Reasonable agreement is found between the double deconvolution and the Bayesian inversion (Fig. 3).

To check the $\delta^{13} \mathrm{C}$ data, we have combined the ice data with the air-archive or the firn $\delta^{13} \mathrm{C}$ data only instead with the in-situ data. Results are not expected to agree perfectly for the different data sets because the number of the firn and air archive data is at the lower limit for our reconstruction. However, results for the 14 firn data points agree surprisingly well with those for the $\approx 1000$ in-situ data ; the peaks in the carbon sinks are at the same years and of comparable magnitude. The agreement between results for the standard case and the air-archive data ( 41 points) is reasonable, although peak occurrence is sometimes offset by 1-2 years.

\section{Conclusion}

Our reconstruction of the evolution of carbon sinks and their natural variability for the last millennium by state of the art $\delta^{13} \mathrm{C}$ and $\mathrm{CO}_{2}$ data reveals fascinating variations. The oceanic sink is modulated by the Southern Oscillation on both interannual and decadal time scales. Interannual variability is of the order of $\pm 1-2 \mathrm{Gt} \mathrm{C} \mathrm{yr}^{-1}$ and significantly correlated with SOI. An increased El Niño activity has probably also lead to a substantially increased oceanic sink around 1940. This suggests that variability in the ocean 
carbon cycle will modulate the future evolution of atmospheric $\mathrm{CO}_{2}$ on interannual to decadal time scales. On the other hand, variability in the oceanic and terrestrial carbon cycle in the 700 years prior to industrialisation was 1-2 orders of magnitude smaller than the anthropogenically forced changes during the last century.

The comparison between single and double deconvolution reveals that the natural oceanic carbon cycle was close to steady state during the last millennium. This supports estimates of the oceanic uptake of anthropogenic carbon by ocean transport models [Schimel et al., 1994] as well as reconstructions based on oceanic measurements of nutrients and dissolved inorganic carbon (e.g. [Gruber ct al., 1996]) where a steady state ocean is assumed.

The role of the terrestrial biosphere changed over time The relatively low atmospheric $\mathrm{CO}_{2}$ between 1600 and 1750 was caused by enhanced terrestrial storage probably in response to regional cooling during the so called "Little Ice Age". Then, the biosphere acted as a source until 1950 as explained by land use emissions up to 1920 . Terrestrial carbon storage was unusually enhanced during the last decades and a sequestration of the order of $100 \mathrm{Gt} \mathrm{C}$ since 1900 remains to be explained by mechanisms such as nutrient fertilization and climate variability or by modification in the land use emission estimates. The reconstructed evolution of the terrestrial sink provides a yard stick for any biosphere model used to project future atmosperic $\mathrm{CO}_{2}$.

Finally, we note that refinements of the temporal resolution of the $\delta^{13} \mathrm{C}$ and $\mathrm{CO}_{2}$ records are necessary to further clarify the role of decadal variability in carbon sinks.

\section{Acknowledgments.}

We thank R. Francey and colleagues for sharing their $\delta^{13} \mathrm{C}$ data prior to publication. We thank C. Folland, P.D. Jacobs, G. Marland, P. Rayner and C. Trudinger for sharing manuscripts and results. We appreciate comments by C. Appenzeller, I. Enting, R. Francey, M. Heimann A. Indermühle, P. Rayner, and T. Stocker. This work was supported by the Swiss National Science Foundation, the Electric Power Research Institute, Palo Alto, Ca, and the International Atomic Energy Agency, Vienna (No 8828/CF).

\section{References}

Andres, R. J., G. Marland, and S. Bischoff, Global and latitudinal estimates of $\delta^{13} \mathrm{C}$ from fossil-fuel consumption and cement manufacture, CDIAC Commun, Spring 1996, 9-10, 1996.

Bacastow, R. B., Modulation of atmospheric carbon dioxide by the southern oscillation, Nature, 261, 116-118, 1976

Bruno, M., and F. Joos, Terrestrial carbon storage during the past 200 years: A Monte Carlo analysis of $\mathrm{CO}_{2}$ data from ice core and atmospheric measurements, Global Biogeochem. Cycles, 11(1), 111-124, 1997.

Enting, I. G., On the use of smoothing splines to filter $\mathrm{CO}_{2}$ data, J. Geophys. Res., 92, 10977-10984, 1987.

Enting, I. G., The incompatibility of ice core $\mathrm{CO}_{2}$ data with reconstructions of biotic $\mathrm{CO}_{2}$ sources (ii). the influence of $\mathrm{CO}_{2}$ fertlised growth, Tellus, 44(B), 23-32, 1992.

Etheridge, D. M., L. P. Steele, R. L. Langenfelds, R. J. Francey, J.-M. Barnola, and V. I. Morgan, Natural and anthropogenic changes in atmospheric $\mathrm{CO}_{2}$ over the last 1000 years from air in Antarctic ice and firn, J. Geophys. Res., 101, 4115-4128, 1996.

Francey, R. J., C. E. Allison, D. M. Etheridge, C. M. Trudinger, I. G. Enting, M. Leuenberger, R. L. Langenfelds, E. Michel, and L. P. Steele, A 1000 year high precision record of $\delta^{13} \mathrm{C}$ in atmospheric $\mathrm{CO}_{2}$, Tellus, In press, 1999.

Francey, R. J., P. P. Tans, C. E. Allison, I. G. Enting, J. W. C. White, and M. Troller, Changes in oceanic and terrestrial carbon uptake since 1982, Nature, 373, 326330, 1995.

Gruber, N., J. L. Sarmiento, and T. F. Stocker, An improved method to detect anthropogenic $\mathrm{CO}_{2}$ in the oceans, Global Biogeochem. Cycles, 10(4), 809-837, 1996.

Houghton, R. A., Changes in terrestrial carbon over the last 135 years, in The Global Carbon Cycle, vol. I15, edited by M. Heimann, pp. 139-157, Springer-Verlag, 1993.

Indermühle, A., T. Stocker, F. Joos, H. Fischer, H. Smith, M. Wahlen, B. Deck, D. Mastroianni, J. Tschumi, T. Blunier, R. Meyer, and B. Stauffer, Holocene carbon-cycle dynamics based on $\mathrm{CO}_{2}$ trapped in ice at taylor dome, Antarctica, Nature, 398, 121-126, 1999.

Joos, F., and M. Bruno, Long-term variability of the terrestrial and occanic carbon sinks and the budgets of the carbon isotopes ${ }^{13} \mathrm{C}$ and ${ }^{14} \mathrm{C}$, Global Biogeochem. Cycles, 12, $277-295,1998$

Keeling, C. D., T. P. Whorf, M. Wahlen, and J. v. d. Pflicht Interannual extremes in the rate of atmospheric carbon dioxide since 1980, Nature, 375, 666-670, 1995.

Mann, M. E., R. S. Bradley, and M. K. Hughes, Globalscale temperature patterns and climate forcing over the past six centuries, Nature, 392, 779-787, 1998.

Marland, G., T. A. Boden, and R. J. Andres, Global, regional and national annual $\mathrm{CO}_{2}$ emission estimates from fossil-fuel burning, hydraulic-cement production and gas flaring: 1950 to 1992, CDIAC Commun., Fall, 20-21, 1995.

Mook, W. G., ${ }^{13} \mathrm{C}$ in atmospheric $\mathrm{CO}_{2}$, Neth. J. Sea Res., 20(2/3), 211-223, 1986.

Parker, D. E., C. K. Folland, and M. Jackson, Marine surface temperature: observed variations and data requirements, Climatic Change, 31, 559-600, 1995.

Rayner, P. J., I. G. Enting, R. J. Francey, and R. Langenfelds, Reconstructing the recent carbon cycle from atmospheric $\mathrm{CO}_{2}, \delta^{13} \mathrm{C}$ and $\mathrm{O}_{2} / \mathrm{N}_{2}$ observations, Tellus, In press, 1999.

Sarmiento, J. L., and E. T. Sundquist, Revised budget for the oceanic uptake of anthropogenic carbon dioxide, $\mathrm{Na}$ ture, 356, 589-593, 1992.

Schimel, D., I. Enting, M. Heimann, T. Wigley, D. Raynaud, D. Alves, and U. Siegenthaler, $\mathrm{CO}_{2}$ and the carbon cycle, in Climate Change 94, Radiative Forcing of Climate Change, edited by J. H. et al., pp. 38-71, Cambridge Univ. Press, New York, 1994

Siegenthaler, U., El Niño and atmospheric $\mathrm{CO}_{2}, \mathrm{Na}$ ture, 345, 295-296, 1990.

Siegenthaler, U., and F. Joos, Use of a simple model for studying oceanic tracer distributions and the global carbon cycle, Tellus, Ser. B, 44, 186-207, 1992.

Siegenthaler, U., and $\mathrm{H}$. Oeschger, Biospheric $\mathrm{CO}_{2}$ emissions during the past 200 years reconstructed by deconvolution of ice core data, Tellus, Ser. B, 39, 140-154, 1987.

Takahashi, T., J. Olafsson, J. G. Goddard, D. W. Chipman, and S. C. Sutherland, Seasonal variation of $\mathrm{CO}_{2}$ and nutrients in the high-latitude surface oceans: a comparative study, Global Biogeochem. Cycles, 7(4), 843-878, 1993.

Trudinger, C. M., I. G. Enting, R. J. Francey, D. M. Etheridge, and P. J. Rayner, Long-term variability in the global carbon cycle inferred from a high precision $\mathrm{CO}_{2}$ and $\delta^{13} \mathrm{c}$ ice core record, Tellus, In press, 1999.

F. Joos, M. Bruno, R. Meyer and M. Leuenberger, Climate and Environmental Physics, Physics Institute, University of Bern, Sidlerstr. 5, CH-3012 Bern, Switzerland. (e-mail:joos@climate.unibe.ch)

(Received January 25, 1999; revised March 24, 1999; accepted March 30, 1999.) 